\title{
Complex Saccharide Metabolism in Cystic Fibrosis Fibroblasts
}

\author{
DANIEL W. WELCH AND R. MICHAEL ROBERTS ${ }^{(38)}$ \\ Department of Biochemistry, University of Florida, Gainesville, Florida, USA
}

\section{Extract}

There are several reports of secretory and other abnormalities present in cultured fibroblasts from patients with cystic fibrosis (CF). We have, therefore, investigated aspects of complex saccharide synthesis and secretion by such cells compared with fibroblasts derived from heterozygous $(\mathrm{HZ})$ parents and from normal $(\mathrm{N})$ children. The main glycosaminoglycans produced by skin fibroblasts during in vitro culture were hyaluronic acid, heparan sulfates, and dermatan sulfate-like materials. Using double-label experiments with $\mathrm{D}-\left[{ }^{3} \mathrm{H}\right]$ - or $\left[{ }^{14} \mathrm{C}\right]$ glucosamine and analyzing the products by ion exchange chromatography, it was shown for five $\mathrm{CF}$, two $\mathrm{HZ}$, and four $\mathbf{N}$ lines that these polysaccharides were secreted into the medium in approximately similar proportions to each other. Moreover, experiments in which three $\mathrm{CF}$, nine $\mathrm{HZ}$, and three $\mathrm{N}$ lines were grown in $\log$ phase for up to 5 days in the presence of $\left[{ }^{35} \mathrm{~S}\right]$ sulfate and $\left[{ }^{3} \mathrm{H}\right]$ glucosamine indicate that, during such a period, CF fibroblasts do not secrete complex carbohydrates at rates significantly different from $\mathrm{N}$ or $\mathrm{HZ}$ cells. Neither do such cells show an abnormal intracellular accumulation of complex carbohydrates. The latter observation was further confirmed by preparing whole cell autoradiographs during growth of six CF, two $\mathrm{HZ}$, and three $\mathrm{N}$ lines in the presence of $\mathrm{D}-\left[{ }^{3} \mathrm{H}\right]$ glucosamine and, subsequently, after addition of unlabeled medium.

\section{Speculation}

Fibroblasts derived from children with cystic fibrosis are not abnormal with regard to their complex carbohydrate metabolism.

Cystic fibrosis is a generalized disorder affecting many, if not all, of the exocrine glands. Although the most consistent difference between a child with $C F$ and the normal individual is a striking increase in the levels of sweat sodium chloride (7), most of the pathologic changes and clinical symptoms are caused by abnormal mucus secretions in the lungs, pancreas, and other mucus-producing glands $(8,16)$ which have led several investigators to propose that the mucus material is either abnormal in quality or produced in abnormally high amounts during the course of the disease. Alternatively, these changes may be a consequence of unusual electrolyte balance in the secretory fluid $(10,11)$. Because the disease is inherited as an autosomal recessive trait (16), attempts have been made to detect abnormalities in cells isolated from $\mathrm{CF}$ individuals $(2-6,9,17,19-21)$, including fibroblasts derived from skin. Many reports have indicated that the $\mathrm{CF}$ fibroblast or its products may be abnormal in some way and that the disease is not, therefore, a primary disorder of the exocrine glands. These cells, for example, have been reported to stain metachromatically with toluidine blue and to contain more glycosaminoglycans than fibroblasts from normal individuals. They have also been reported to have an abnormally high rate of glycosaminoglycan synthesis with increased release of these compounds into the medium. However, Wiesmann and Neufeld (29), using ${ }^{35} \mathrm{~S}$-sulfate, have indicated that $\mathrm{CF}$ fibroblasts do not accumulate or secrete sulfated polysaccharides at abnormally high rates. Because of this controversy, we have re-examined this phenomenon, particularly in view of the fact that hyaluronic acid, a nonsulfated polymer, is the major glycosaminoglycan produced by skin fibroblasts.

\section{METHODS}

\section{CELL CULTURES}

Skin biopsies from CF children (aged between 3 and 10 years) were obtained from patients treated at the CF clinic of the Jacksonville Baptist Memorial Hospital, Jacksonville, Florida, or admitted into the J. Hillis Miller Health Center in Gainesville, Florida. All of the CF patients had high sodium levels in their sweat and had severe pulmonary or pancreatic involvement. Skin biopsies of heterozygotes were obtained from parents of $\mathrm{CF}$ children and were not, therefore, age-matched with the contrasting lines. Normal material was derived from foreskins. After establishing monolayer culture, the fibroblasts were trypsinized and subcultured into $75 \mathrm{~cm}^{2}$ Falcon flasks (30). When confluent, they were subcultured into two flasks. All experiments were performed on cells which had undergone between 4 and 10 such 1:2 passages.

Cultures were grown at $37^{\circ}$ in an atmosphere of $95 \%$ air and $5 \%$ $\mathrm{CO}_{2}$. They were maintained in $18 \mathrm{ml}$ Eagle's minimum essential medium (MEM) in Earle's salts reinforced with $16.7 \%(\mathrm{v} / \mathrm{v})$ heat-inactivated fetal calf serum (30) and containing antibioticantimycotic mixture (31). Cells were counted using a Coulter counter.

\section{CHEMICALS AND RADIOCHEMICALS}

D-[1-14 C]Glucosamine $(53 \mu \mathrm{Ci} / \mu \mathrm{mol}), \quad \mathrm{D}-\left[1-{ }^{3} \mathrm{H}\right]$ glucosamine $(2.6 \mathrm{mCi} / \mu \mathrm{mol})$, and $\left[{ }^{35} \mathrm{~S}\right]$ sulfate $(92 \mathrm{mCi} / \mu \mathrm{mol})$ were products of Amersham-Searle Corporation. Chondroitin-4-sulfate, chondroitin-6-sulfate, dermatan sulfate (chondroitin sulfate B), and hyaluronic acid were obtained from Seikagaku Kogy Company, Ltd. (32).

\section{LABELING EXPERIMENTS}

Comparisons have been made using double-labeling techniques, employing either ${ }^{14} \mathrm{C}$ and ${ }^{3} \mathrm{H}$ or ${ }^{35} \mathrm{~S}$ and ${ }^{3} \mathrm{H}$. D-Glucosamine was used as a precursor of glycoproteins, glycosaminoglycans, and other molecules containing amino sugar derivatives. $\left[{ }^{35}\right.$ S]Sulfate was used as a precursor of sulfated materials. The concentration of unlabeled sulfate in the medium was not reduced in our experiments using ${ }^{35} \mathrm{~S}$, so that total counts incorporated were relatively low compared with the experiments of other workers (29).

In experiments with roller bottles $\left(750 \mathrm{~cm}^{2}\right)$, approximately 20 $\times 10^{6}$ fibroblasts (from two confluent Falcon flasks) were introduced into $100 \mathrm{ml}$ radioactive medium. The bottles were tightly capped and rotated slowly $(0.1 \mathrm{rpm})$ ar $37^{\circ}$ for 3 days. 


\section{PROCESSING OF CELLS}

The radioactive medium was collected from each bottle and stored frozen. The monolayer was then washed twice with Hank's balanced salt solution, and cells were detached using $0.25 \%$ trypsin. The suspension was centrifuged at $500 \times g$ to pellet the cells and the supernatant fraction (trypsinate) collected. The cells were washed once with salt solution, recentrifuged, and ground up in hot $80 \%(\mathrm{v} / \mathrm{v})$ ethanol using a motor-driven ground glass homogenizer. Particulate matter from the extract was centrifuged $(10,000 \times g)$, washed twice with $80 \%$ ethanol, and solubilized by heating at $100^{\circ}$ with $1 \mathrm{ml}$ of $2 \%(\mathrm{w} / \mathrm{v})$ sodium dodecyl sulfate in $0.1 \mathrm{M}$ phosphate buffer.

Portions of the radioactive medium were combined suitably to allow appropriate comparisons to be made (e.g., between ${ }^{3} \mathrm{H}$ labeled $\mathrm{CF}$ cultures and ${ }^{14} \mathrm{C}$-labeled normals) and then digested exhaustively with Pronase (25). A tenth volume of $0.1 \mathrm{M}$ disodium EDTA was then added to chelate divalent cations and to prevent precipitation of polyanionic material by $\mathrm{Ca}^{2+}$. After centrifuging to remove any particulate matter, the solutions were desalted on a column $(100 \times 2.5 \mathrm{~cm})$ of BioRad Bio-Gel P-2 (33). Materials eluting at the void front were collected, concentrated, and subjected to gel filtration on a column $(74 \times 2.5 \mathrm{~cm})$ of Bio-Gel P-100 equilibrated with $0.01 \mathrm{M}$ phosphate buffer $\mathrm{pH}$ 7.0. After P-100 chromatography glycosaminoglycans were fractionated by ion exchange chromatography on a column of DEAE-cellulose (acetate form; $1.0 \times 15 \mathrm{~cm}$ ) using a linear gradient of ammonium acetate $(0.01-2.5 \mathrm{M})(25)$.

Isolation of Hyaluronic Acid from Medium. In the experiments in which cells were labeled simultaneously with $\left[{ }^{35} \mathrm{~S}\right]$ sulfate and D- $\left[1-{ }^{3} \mathrm{H}\right]$ glucosamine (Figs 3, 4, and 5) samples of media were first dialyzed for $48 \mathrm{hr}$. Trichloroacetic acid $(15 \% \mathrm{w} / \mathrm{v})$ was then added until its concentration was $7.5 \%(\mathrm{w} / \mathrm{v})$. This preparation was kept at $3^{\circ}$ for $4 \mathrm{hr}$ and the precipitate was collected by centrifugation. The pellet was washed twice with $7.5 \%(\mathrm{w} / \mathrm{v})$ trichloracetic acid and then solubilized by heating in $2 \mathrm{ml}$ of $2.0 \%$ $(\mathrm{w} / \mathrm{v})$ sodium dodecyl sulfate in $0.1 \mathrm{M}$ phosphate buffer. The trichloroacetic acid-soluble fraction, which was considered to contain most of the glycosaminoglycans, was dialyzed against water before radioactivity measurements. Approximately $80 \%$ of the ${ }^{3} \mathrm{H}$ radioactivity of this fraction was recovered as hyaluronic acid after ion exchange chromatography.

Determination of Radioactivity. The radioactivity in aqueous samples $(0.5 \mathrm{ml})$ was determined after addition of $5 \mathrm{ml}$ of toluene-Triton X-100 scintillant (27) using a Packard-Tri-Carb or Beckman LS-300 scintillation spectrometer. ${ }^{14} \mathrm{C}$ and ${ }^{35} \mathrm{~S}$ were counted with about $95 \%$, and ${ }^{3} \mathrm{H}$ with about $25 \%$ efficiency. In the dual-label experiments the channels were so adjusted that no counts from ${ }^{3} \mathrm{H}$ were detected in the ${ }^{14} \mathrm{C}$ channel, whereas the extent of overlap of ${ }^{14} \mathrm{C}$ into the ${ }^{3} \mathrm{H}$ channel was held at a fixed value, usually about $40 \%$, depending upon the instrument. Similar methods were used to distinguish ${ }^{3} \mathrm{H}$ and ${ }^{35} \mathrm{~S}$. Samples were checked for quench using the external channels ratio. Final values were computed using a Wang model 700 series programmable calculator. ${ }^{35} \mathrm{~S}$ values were all corrected for decay.

In order to make comparison of results simpler, all radioactivity data for gel and column eluate profiles are presented as percentages of the total ${ }^{14} \mathrm{C}$ or ${ }^{3} \mathrm{H}$ recovered from the gel or column.

Paper Chromatography. Amino sugars were identified in the following two solvents which separate glucosamine from galactosamine: solvent $A$, butan-1-ol-pyridine- $0.1 \mathrm{M} \mathrm{HCl}(5: 3: 2$, by volume); solvent $B$, pyridine-ethyl acetate-acetic acid-water $(5: 5: 3: 1$, by volume) in a tank equilibrated with pyridine-ethyl acetate-water (11:40:6, by volume).

Radioactive regions were detected by chromatogram scanning. Amino sugar standards were detected by either alkaline- $\mathrm{AgNO}_{3}$ spray reagent or by ninhydrin dissolved in butan-1-ol.

Methods for Identification of Glycosaminoglycans. Polysaccharides were separated by ion exchange chromatography (13), and by electrophoresis on cellulose acetate strips using a Beckman model
R-100 MicroZone electrophoresis system. Electrophoresis was carried out in $0.1 \mathrm{M}$ barium acetate, $\mathrm{pH} 8$ (28) or in $0.1 \mathrm{M}$ pyridine- $0.566 \mathrm{M}$ formic acid buffer $\mathrm{pH} 3.0$ (15). A constant voltage of $140 \mathrm{~V}$ giving a current of approximately $0.5 \mathrm{~mA} / \mathrm{cm}$ was used for $45 \mathrm{~min}$. Strips were stained using toluidine blue $(0.05 \%$ in $65 \% \mathrm{v} / \mathrm{v}$ ethanol). Radioactivity $\left({ }^{14} \mathrm{C}\right.$ or $\left.{ }^{35} \mathrm{~S}\right)$ was detected by autoradiography on Kodak $\mathrm{x}$-ray film; ${ }^{3} \mathrm{H}$ was detected by cutting the strips into $1-\mathrm{mm}$ pieces and counting by liquid scintillation.

Testicular hyaluronidase (34) digestions were carried out at $\mathrm{pH}$ 5.3 for $24 \mathrm{hr}$ at $37^{\circ}$, using a large excess of enzyme.

Nitrous acid degradations were performed according to the method of Kraemer (12).

Autoradiography. Cells were grown in petri dishes, each containing five or six sterile coverslips. The cells were allowed to incorporate radioactivity from medium containing $\mathrm{D}-\left[{ }^{3} \mathrm{H}\right]$ glucosamine $(50 \mu \mathrm{Ci} / 10 \mathrm{ml})$ for 3 days after passage. This radioactive "pulse" was followed for a further 3 days in unlabeled medium. Coverslips were removed daily, washed, and fixed and attached to microscope slides with the cell monolayer facing upwards. Slides were dipped in Kodak NTB2 liquid emulsion, and the autoradiograph was exposed for 1-2 days. After development, the autoradiographs were stained using $0.1 \%$ toluidine blue $O$ in water. Silver grains were counted either over individual cells of roughly similar size (approximately $100 \times 50 \mu \mathrm{m})$, or over a grid field $(100 \times 100$ $\mu \mathrm{m}$ ) with subsequent division by the number of nuclei counted in the same field. At least 20 determinations in different fields were made for each coverslip and standard deviations calculated.

We tested a number of fixation methods including methanol, ethanol-acetic acid ( $3: 1$ by volume) $5 \%(\mathrm{w} / \mathrm{v})$ glutaraldehyde in 0.1 $\mathrm{M}$ phosphate buffer, $\mathrm{pH} 7.3$. Although all of these gave comparable results, we normally used a 2-min fixation in absolute methanol. Hyaluronic acid and other polysaccharides are insoluble in this solvent.

\section{RESULTS}

\section{IDENTIFICATION OF EXTRACELLULAR GLYCOSAMINOGLYCANS}

In order to identify the glycosaminoglycans produced by the fibroblasts, cells were grown in roller bottles containing MEM medium plus either ${ }^{14} \mathrm{C}$ - or ${ }^{3} \mathrm{H}$-labeled D-glucosamine. After 3

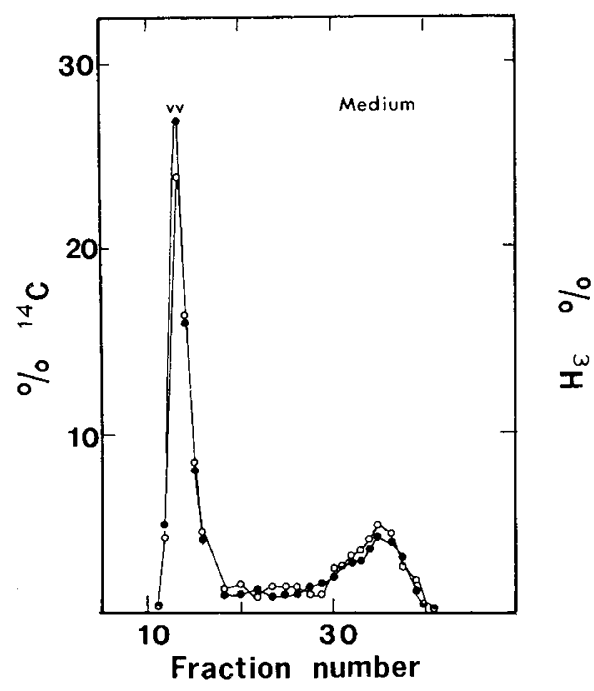

Fig. 1. Bio-Gel P-100 chromatography of the Pronase-digested materials from the medium after providing fibroblasts with $\mathrm{D}-\left[{ }^{3} \mathrm{H}\right]-$ or $\mathrm{D}-\left[{ }^{14} \mathrm{C}\right]$. glucosamine for 3 days. The void volume of the column is indicated $(v v)$. Radioactivity data is presented to show percentage of total recovered ${ }^{3} \mathrm{H}$ or ${ }^{14} \mathrm{C}$. The cystic fibrosis line (line 13) $(\mathrm{O}-\mathrm{O})$ was provided with $\mathrm{D}$ $\left[{ }^{3} \mathrm{H}\right]$ glucosamine, the normal line (line 21 ) with D- $\left[{ }^{14} \mathrm{D}\right]$ glucosamine. The eluant was water. 


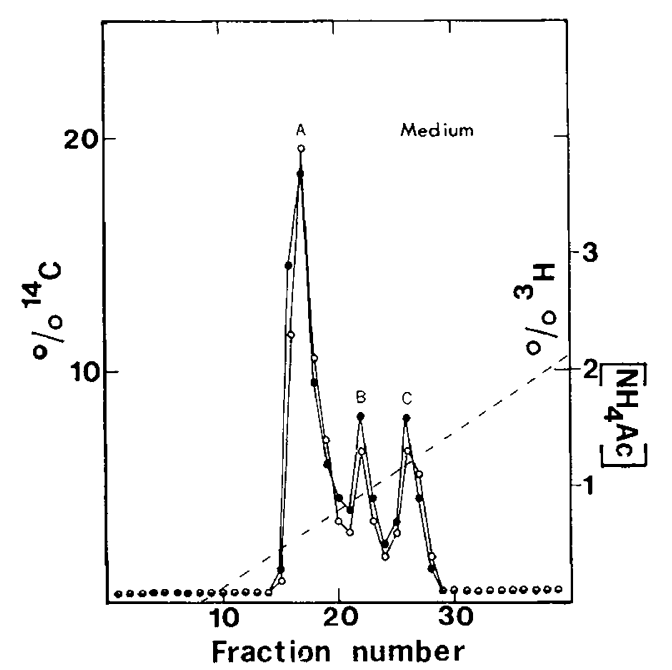

Fig. 2. Ion exchange chromatography of the radioactive material from the growth medium that was collected in the void volume during Bio-Gel P-100 chromatography (Fig. 1). Radioactivity data is presented as percentages of total recovered ${ }^{3} \mathrm{H}$ or ${ }^{14} \mathrm{C}$. The gradient of ammonium acetate is indicated by the broken line. $\mathrm{O}-\mathrm{O}$ : cystic fibrosis, ${ }^{3} \mathrm{H}$; -—- normal, ${ }^{14} \mathrm{C}$.

days the medium for each bottle was collected, treated with Pronase, concentrated and finally desalted on a column of Bio-Gel P-2. Materials eluting at the void front were again concentrated and chromatographed on a column of Bio-Gel P-100 (Fig. 1). Two main peaks of radioactivity were detected, one which eluted at the void front and a second which was considerably retarded. Figure 1 illustrates a typical dual-label experiment which was run in order to compare material isolated from CF fibroblasts with those from normal line. The profiles coincide very closely, indicating a similar proportion of low and high molecular weight products from both groups of cells. The material at the void front was then subjected to ion exchange chromatography (Fig. 2). Three peaks of radioactivity were resolved by the salt gradient. The first major peak (peak A), which contained over $70 \%$ of the radioactivity cochromatographed with hyaluronic acid. It was further identified by electrophoresis on cellulose acetate strips. Peak A was also degraded by hyaluronidase to fragments of low molecular weight and after acid hydrolysis, yielded radioactive glucosamine and not galactosamine. Moreover, after providing $\left[{ }^{35} \mathrm{~S}\right]$ sulfate to fibroblasts, peak A does not become labeled.

Peak B contains component(s) which migrate close to the heparan sulfate region upon electrophoresis. The major labeled amino sugar present is glucosamine. Further, the material in peak $\mathrm{B}$ is extensively degraded by treatment with nitrous acid so that after rechromatography on a column of Bio-Gel P-100 about $50 \%$ of the radioactivity appears in the included volume, presumably as compounds of low molecular weight.

Peak $\mathrm{C}$ has the chromatographic and electrophoretic mobility of dermatan sulfate and its major amino sugar component is galactosamine.

We conclude tentatively that the major acidic mucopolysaccharides secreted into the medium by human skin fibroblasts in culture are hyaluronic acid, heparan sulfates, and dermatan sulfate. Moreover, in comparative experiments using $5 \mathrm{CF}$ (lines 13,23, 31,51 , and 69), $4 \mathrm{~N}$ (lines $21,25,27$, and 37), and $2 \mathrm{HZ}$ cell lines we have found no indication that any of these polymers are produced in unusual relative proportions by any group of cells, provided that the analyses are performed on materials isolated from cultures maintained under identical growth conditions.

\section{RELATIVE RATES OF POLYSACCHARIDE SECRETION BY FIBROBLASTS}

Experiments described in the previous section indicate that the different groups of fibroblasts produced qualitatively similar glycosaminoglycans in roughly similar relative proportions. Therefore, we investigated whether CF fibroblasts are producing quantitatively greater amounts of complex saccharides than the normal or heterozygous cells.

Cells from different lines representing CF, normal, and heterozygous individuals were transferred to Falcon flasks $\left(75 \mathrm{~cm}^{2}\right)$ with $15 \mathrm{mi}$ of fresh MEM medium containing D- $\left[1-{ }^{3} \mathrm{H}\right]$ glucosamine $(10$ $\mu \mathrm{Ci})$ and $10 \mu \mathrm{Ci}\left[{ }^{35} \mathrm{~S}\right]$ sulfate. Each flask received between $1.5 \times$ $10^{6}$ and $1.6 \times 10^{6}$ cells, and each cell line, which was between its fifth and eighth passage in culture, was run in duplicate. A total of $3 \mathrm{~N}$ (lines 35, 37, and 39), $9 \mathrm{HZ}$, and $3 \mathrm{CF}$ (lines 51, 55, and 65) lines were employed. The radioactivity incorporated from $\left[{ }^{35} \mathrm{~S}\right]$ sulfate was relatively low compared with the ${ }^{3} \mathrm{H}$ because of the high concentration of unlabeled sulfate present in the growth medium.

One-milliliter aliquots were removed from the medium of each flask daily for 5 days. These samples were dialyzed at $3^{\circ}$ for 2 days against several changes of distilled water. Radioactivity in the total nondiffusible material and in its trichloroacetic acid-soluble and insoluble components was then measured. Figure 3 shows the appearance of ${ }^{35} \mathrm{~S}$ in total macromolecular material in the dialyzed medium. This largely represents heparan sulfate and dermatan sulfate-like compounds. It is clear from these results that there were large differences in the total amounts of such compounds secreted by the different cell lines, but that although the $\mathrm{CF}$ fibroblasts fell within the lower range of values, they were not significantly different from $\mathrm{N}$ or $\mathrm{HZ}$ cells.

Radioactivity from D-glucosamine is incorporated into both glycoproteins and glycosaminoglycans. The former are largely precipitated by trichloroacetic acid, whereas a high proportion of the latter materials are soluble (13). In our experiments, however, about $30 \%$ of the ${ }^{35} \mathrm{~S}$ was recovered in the precipitate. However, more than $90 \%$ of the hyaluronic acid which was not labeled with

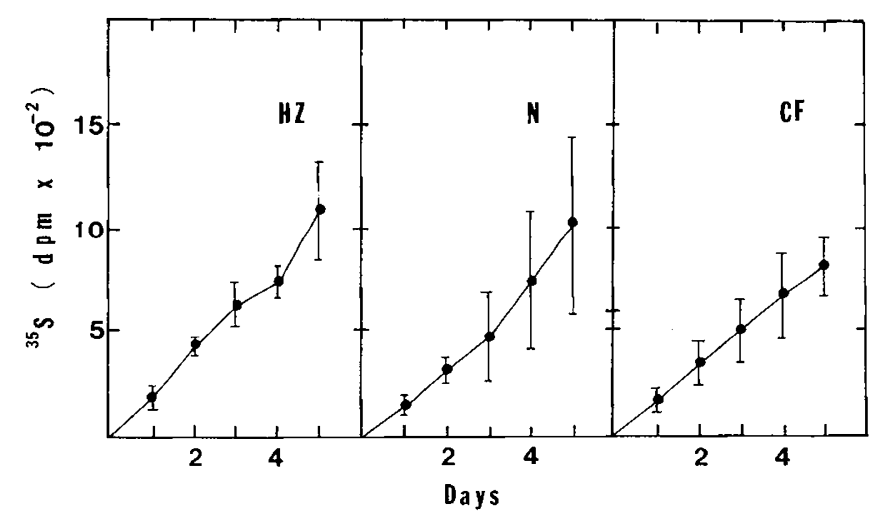

Fig. 3. Appearance of ${ }^{35} \mathrm{~S}$ in nondiffusible (macromolecular) material in the medium of skin fibroblasts. $H Z$ : heterozygotes; $N$ : cells from normal children; $C F$ : cells from children with cystic fibrosis. Standard deviations are shown for each time point.

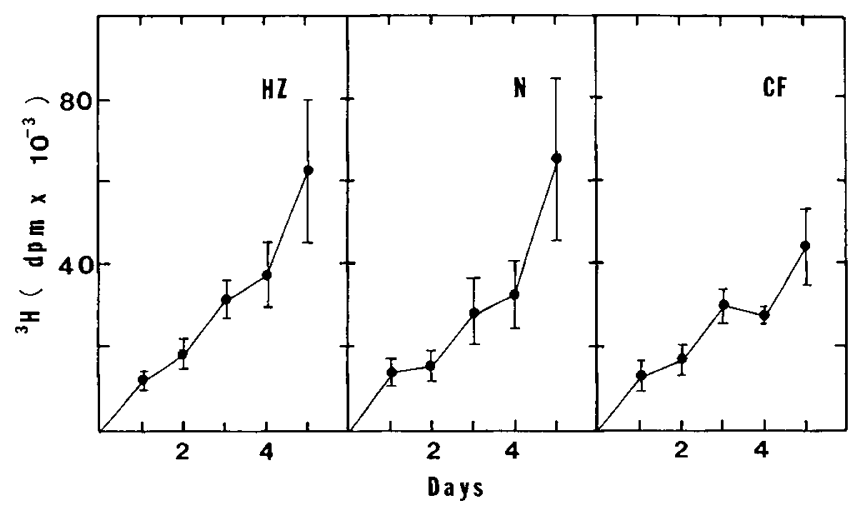

Fig. 4. Appearance of ${ }^{3} \mathrm{H}$ from $\mathrm{D}-\left[{ }^{3} \mathrm{H}\right]$ glucosamine in trichloroacetic acid-precipitable $(12.5 \% \mathrm{w} / \mathrm{v})$ material in the growth medium of skin fibroblasts. $H Z$ : heterozygotes; $N$ : normal children; $C F$ : cystic fibrosis. 


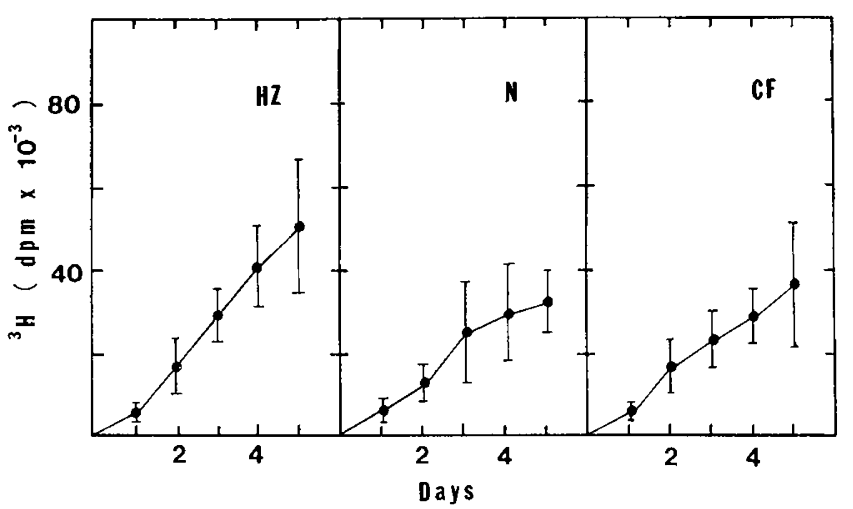

Fig. 5. Appearance of ${ }^{3} \mathrm{H}$ from $\mathrm{D}-\left[{ }^{3} \mathrm{H}\right]$ glucosamine in trichloroacetic acid soluble, nondialyzable material in the growth medium of skin fibroblasts. $H Z$ : heterozygotes; $N$ : normal children; $C F$ : cystic fibrosis.

Table 1. Radioactivity in dialyzed media after growing fibroblast lines for 5 days on $D-\left[{ }^{3} \mathrm{H}\right]$ glucosamine and $\left[{ }^{35} \mathrm{~S}\right]$ sulfate

\begin{tabular}{lcc}
\hline \multicolumn{1}{c}{ Cell type } & $\begin{array}{c}{ }^{3} \mathrm{H} \text { label, dpm/mg } \\
\text { cell protein } \times 10^{-3}\end{array}$ & $\begin{array}{c}{ }^{32} \mathrm{~S} \text { label, dpm } / \mathrm{mg} \\
\text { cell protein }\end{array}$ \\
\hline Normal & $8,750 \pm 3,400$ & $6,910 \pm 3,640$ \\
Heterozygote & $6,620 \pm 1,990$ & $5,240 \pm 1,180$ \\
Cystic fibrosis & $4,070 \pm 1,760$ & $3,390 \pm 480$ \\
\hline
\end{tabular}

Table 2. Accumulated ethanol-insoluble radioactivity in fibroblast cells after 5-days of growth on $D-\left[{ }^{3} \mathrm{H}\right]$ glucosamine and $\left[{ }^{35}\right.$ S $]$ sulfate

\begin{tabular}{lccc}
\hline Cell type & $\begin{array}{l}{ }^{3} \mathrm{H} \text { label, dpm } / \mathrm{mg} \\
\text { cell protein } \times 10^{-3}\end{array}$ & $\begin{array}{c}{ }^{32} \text { S label, dpm } / \mathrm{mg} \\
\text { cell protein }\end{array}$ & $\begin{array}{c}\text { Cell } \\
\text { doubling } \\
\text { time, hr }\end{array}$ \\
\hline Normal & $419 \pm 60$ & $638 \pm 331$ & $38 \pm 5$ \\
Heterozygote & $248 \pm 121$ & $626 \pm 49$ & $38 \pm 5$ \\
Cystic fibrosis & $183 \pm 93$ & $488 \pm 107$ & $49 \pm 7$ \\
\hline
\end{tabular}

${ }^{35} \mathrm{~S}$ remained with the supernatant fraction and this compound accounted for most ( $>80 \%$ ) of the trichloroacetic acid-soluble ${ }^{3} \mathrm{H}$ radioactivity. Figures 4 and 5 show the appearance of ${ }^{3} \mathrm{H}$ in trichloroacetic acid-soluble and insoluble macromolecules. Again, although the $\mathrm{CF}$ fibroblasts seemed, on average, biosynthetically less active than the majority of the heterozygous lines we have tested, they did not fall significantly out of the normal range. Our results also imply that hyaluronic acid production is probably not abnormally increased in CF fibroblasts.

Although we have not undertaken a detailed cell cycle analysis of any of our fibroblast lines we have made a measure of their approximate doubling times in culture (Table 1). It seemed to us that the results in Figures 4.6 might correlate better with the generation times and hence possible metabolic rates of the cells than with the CF disease state. We have also expressed the amounts of ${ }^{35} \mathrm{~S}$ and ${ }^{3} \mathrm{H}$ macromolecular radioactivity in the medium at the end of the 5-day growth period in terms of the amount of cellular protein recovered from the Falcon dishes (Table 2). Our results would appear to confirm that, in general, the cells with the shortest generation times and therefore, those likely to be most biosynthetically active, tend to produce more extracellular material than the slow growing lines.

\section{ACCUMULATION OF COMPLEX SACCHARIDES BY FIBROBLASTS}

Table 2 lists the amount of ${ }^{3} \mathrm{H}$ and ${ }^{35} \mathrm{~S}$ in ethanol-insoluble material recovered from the cells at the end of the 5-day growth period in relation to total cellular protein. Amounts were relatively low compared with those in the medium. With respect to both ${ }^{3} \mathrm{H}$ and ${ }^{35} \mathrm{~S}$ the $\mathrm{CF}$ and normal lines fell within, or very ctose to, the range encompassed by the larger group of heterozygotes. Indeed, on the average, $C F$ cells accumulated rather less radioactivity than the contrasting lines, suggesting that there was no abnormal build-up of complex carbohydrates within such cells.

In another series of experiments we have prepared autoradiographs from cells administered D- $\left[1-{ }^{3} \mathrm{H}\right]$ glucosamine. The cells were grown on coverslips for 3 days in presence of radioactive label (the "pulse") and then transferred to nonradioactive medium for several days. Autoradiographs were prepared daily throughout the experiments and silver grains counted over individual cells. We felt that this might indicate whether CF fibroblasts were accumulating complex saccharide material containing amino sugar residues. The results of two such experiments are shown in Figure 6. There was an approximately linear increase in radioactivity during the pulse, indicating that the cells had not reached constant specific activity. During the period on unlabeled medium all groups of cells showed a fairly similar decline in their incorporated radioactivity. There was no suggestion that the CF cells retained or accumulated labeled macromolecules in significantly higher amounts than normal cells during either the pulse period or the subsequent chase. This has been confirmed in experiments with two other CF lines.

\section{DISCUSSION}

In this study we have made a number of comparisons between fibroblasts derived from children with cystic fibrosis, from heterozygous parents of such children, and from normal individuals. We have investigated: ( 1 ) the qualitative nature of the glycosaminoglycans which are secreted into the medium; (2) the relative rates of glycosaminoglycan and glycoprotein secretion by different lines; (3) the intracellular accumulation of complex saccharides by the cells. In no instance have we been able to detect any major qualitative or quantitative differences which might distinguish the CF fibroblast from normal cells. However, even though we have attempted to maintain valid comparisons by using cells in similar passage number and under similar conditions of growth, it is clear that large quantitative differences in metabolic activity can be observed between individual lines, even within the same gorup. Such marked variation between cells might account for the apparent differences between CF and normal fibroblasts in com-

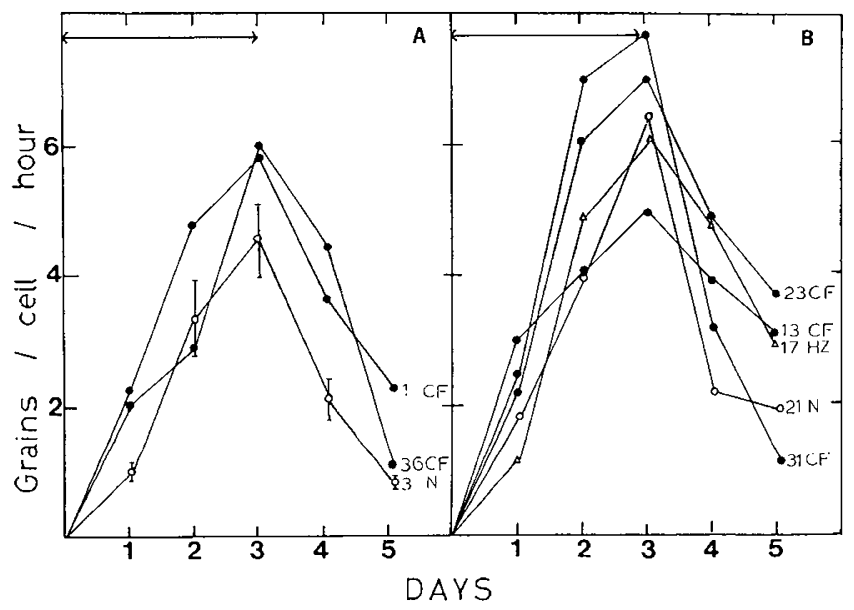

Fig. 6. Numbers of silver grains counted over fibroblast cells provided with $\mathrm{D}-\left[{ }^{3} \mathrm{H}\right]$ glucosamine $(50 \mu \mathrm{Ci} / 10 \mathrm{ml}$ medium) for 3 days (indicated by arrow) and then transferred to unlabeled medium. Coverslips with attached cells were removed daily and whole cell autoradiographs prepared. For clarity, the standard deviations for each point have been omitted except for the normal $(N)$ line in $A . A$ and $B$ are separate experiments performed several months apart. $C F$ : cystic fibrosis; $N$ : normal; $H Z$ : heterozygote. The numbers preceding this classification refer to our stock numbers. Five $\mathrm{CF}$, two $\mathrm{N}$, and one $\mathrm{HZ}$ line were tested in these experiments. 
plex saccharide metabolism that have been reported by others $(4,17)$.

The dual-label experiments, which allow qualitative comparisons to be made under identical chromatographic conditions, have indicated that the proportions of the different glycosaminoglycans produced by the different fibroblast lines are relatively constant. As with other cell lines of fibroblast origin, hyaluronic acid is the major polysaccharide produced $(1,14,15)$. Heparan sulfate-like polymers are also present. These compounds appear to be ubiquitous products of cells in culture $(13,23)$. Those from the human fibroblast are excluded from Bio-Gel 100, indicating that they are of greater size than heparan sulfates from Chinese hamster ovary cells which have been reported to have molecular weights between 5,000 and $10,000(12,13)$.

One observation concerning the recognition of CF in cultured cells that has been especially controversial is whether the $\mathrm{CF}$ fibroblast or lymphocyte stains metachromatically with toluidine blue or with other basic dyes. CF fibroblasts have also been reported to have large, conspicuous lysosomes (2). Together, these results suggest that $C F$ cells were accumulating acidic material, most probably glycosaminoglycans. On the other hand, others have been unable to reproduce these results consistently $(18,19,24$, 26) and we have also failed to obtain the staining reaction except on very sparse or confluent cultures, which were growing poorly. In these instances normal cells also tend to stain. Our results using radioactive D-glucosamine and sulfate and those of Wiesmann and Neufeld with sulfate alone (29) suggest most strongly that CF cells do not show an unusual accumulation of complex carbohydrate material of any kind under normal conditions of growth.

However, Danes and Bearn (5) did indicate considerable familial heterogeneity in the metachromatic staining of different CF lines in culture, and the disease itself is clinically highly variable. It may be that the CF lines we have used, although genetically unrelated, represent an atypical group of CF individuals. We cannot rule this out. However, it is apparent that none of the characteristics we have investigated give an indication of the underlying metabolic basis of the disease. Nor could they be valuable in either pre- or postnatal diagnosis of $\mathrm{CF}$.

\section{SUMMARY}

Skin fibroblasts derived from children with cystic fibrosis secreted the same glycosaminoglycans in approximately similar proportions and at similar rates as cells from normal individuals. Neither did such cells accumulate complex saccharides intracellularly in amounts significantly different from normal.

\section{REFERENCES AND NOTES}

1. Bader, J. P., Ray, D. A., and Steck, T. L.: Electrophoretic determinations of hyaluronate produced by cells in culture. Biochem. Biophys. Acta, 264: 73 (1972).

2. Bartman, J., Wiesmann, U., and Blanc, W. A.: Ultrastructure of cultivated fibroblasts in cystic fibrosis of the pancreas. J. Pediat., 76:430 (1970).

3. Danes, B. S., and Bearn, A. G.: A genetic cell marker in cystic fibrosis of the pancreas. Lancet, $i$ : 1061 (1968).

4. Danes, B. S., and Bearn, A. G.: Cystic fibrosis: Distribution of mucopolysaccharides in fibroblast cultures. Biochem. Biophys. Res. Commun., 36: 191 (1969).

5. Danes, B. S., and Bearn, A. G.: Cystic fibrosis of the pancreas: a study in cell culture. J. Exp. Med., 129: 775 (1969).

6. Danes, B. S., Foley, K. M., Dillon, S. D., and Bearn, A. G.: Genetic study of cystic fibrosis of the pancreas using white blood cell cultures. Nature, 222 . 685 (1969).

Copyright @ 1975 International Pediatric Research Foundation, Inc.
7. di Sant' Agnese, P. A., Darling, R. C., Perera, G. A., and Shea, E.: Abnormal electrolyte composition of sweat in cystic fibrosis of the pancreas. Pediatrics, 12: 549 (1953).

8. di Sant'Agnese, P. A., and Talamo, R. C.: Pathogenesis and physiopathology of cystic fibrosis of the pancreas. New Engl. J. Med., 277: 1344, 1399 (1967).

9. Fitzpatrick, D. F., Landon, E. J., James, J.: Serum binding of calcium and the red cell membrane in cystic fibrosis. Nature New Biol., 235: 173 (1972).

10. Gibson, L. E., Matthews, W. J., Manihan, P. J., and Patti, J. A.: Relating mucus, calcium and sweat in a new concept of cystic fibrosis. Pediatrics, 48: 695 (1971).

11. Gugler, E., Pallavicini, E. J., Swerflow, H., and di Sant' Agnese, P. A.: The role of calcium in submaxillary saliva of patients with cystic fibrosis. J. Pediat., 71: $585(1967)$.

12. Kraemer, P. M.: Heparan sulfate of cultured cells. I. Membrane associated and cell subspecies in Chinese hamster cells. Biochemistry, 10: 1437 (1971).

13. Kraemer, P. M.: Heparan sulfates of cultured cells. II. Acid-soluble and precipitable species of different cell lines. Biochemistry, 10: 1445 (1971).

14. Kraemer, P. M.: Complex carbohydrates of animal cells: Biochemistry and physiology of the cell periphery. In: L. A. Manson: Biomembranes, Vol. I, p. 67 (Plenum Press, New York, 1971).

15. Kondo, K., Seno, N., and Anno, K.: Mucopolysaccharides from chicken skin of three age groups. Biochim. Biophys. Acta, 244: 513 (1971)

16. Lobeck, C. C.: Cystic fibrosis. In: J. B. Stanbury, J. B. Wyngaarden, and D. S. Fredrickson: The Metabolic Basis of Inherited Disease, p. 1605 (McGraw-Hill Book Company, Inc., New York, 1972).

17. Matalon, R., and Dorfman, A.: Acid mucopolysaccharides in cultured fibroblasts of cystic fibrosis of the pancreas. Biochem. Biophys. Res. Commun., 33: 954 (1968).

18. Milunsky, A., and Littlefield, J. W.: Diagnostic limitations of metachromasia. New Engl. J. Med., 28I: 1128 (1969).

19. Nadler, H. L., Swae, M. A., Wodnicki, J. M., and O'Flynn, M. E.: Cultivated amniotic fluid cells and fibroblasts derived from families with cystic fibrosis. Lancet, 2: 84 (1969)

20. Pallavicini, J. C., Wiesmann, U., Uhlendorf, W. B., and di Sant' Agnese, P. A.: Glycogen content of tissue culture fibroblasts from patients with cystic fibrosis and other heritable disorders. J. Pediat., 77: 280 (1970).

21. Rennert, O. M., Frias, J. L.; Julius, R. L., and LaPointe, D.: The detection of the heterozygote and homozygote in cystic fibrosis by short term lymphocyte culture studies: A defect in RNA methylation. Clin. Pediat., 11: 351 (1972)

22. Rennert, O. M., Frias, J., and LaPointe, D.: Methylation of RNA acid polyamine metabolism in cystic fibrosis. In: J. A. Mangos, and R. C. Talamo, Fundamental Problems of Cystic Fibrosis and Related Diseases, p. 4I (Intercontinental Medical Book Corporation, New York, 1973).

23. Satoh, C., Duff, R., Rapp, F., and Davidson, E. A.: Production of mucopolysaccharides by normal and transformed cells. Proc. Nat. Acad. Sci. U.S.A., 70: 54 (1973).

24. Schubert, M., and Hamerman, D: Metachromasia; chemical theory and histochemical use. J. Histochem. Cytochem., 4: 159 (1956).

25. Spiro, R. G.: The carbohydrate units of thyroglobulin. J. Biol. Chem., 240: 1603 (1965).

26. Taysi, K., Kistenmacher, M. L., Punnett, H. H., and Mellman, W. J.: Limitations of metachromasia as a diagnostic aid in pediatrics. New Engl. J. Med., 281: 1108 (1969)

27. Turner, J. C.: Triton X-100 scintillant for ${ }^{14} \mathrm{C}$-labelled materials. Int. J. Appl. Radiat. Isotop., 19: 557 (1968).

28. Wessler, E.: Analytical and preparative separation of acidic glycosaminoglycans by electrophoresis in barium acetate. Anal. Biochem, 26: 439 (1968).

29. Wiesmann, U., and Neufeld, E. F.: Metabolism of sulfated mucopolysaccharide in cultured fibroblasts from cystic fibrosis patients. J. Pediat., 77: 685 (1970).

30. Bioquest, Cockeysville, $\mathrm{Md}$

31. Grand Island Biological Co., Grand Island, N. Y.

32. Tokyo, Japan.

33. BioRad Laboratories, Richmond, Calif.

34. Sigma Chemical Co. St Louis, Mo.

35. The authors thank Drs. O. M. Rennert, R. Julius, and W. C. Kelly for obtaining biopsy specimens.

36. This research was supported by grants from the National Institutes of Health (AM-15023) and the National Cystic Fibrosis Foundation.

37. Dan Welch is supported by National Institutes of Health Medical Scientist Fellowship GM56024 and Dr. R. M. Roberts by Career Development Award K04AM 70,389.

38. Requests for reprints should be addressed to: R. M. Roberts, Ph.D., The J. Hillis Miller Health Center, Department of Biochemistry, University of Florida, Gainesville, Fla. 32610 (USA).

39. Accepted for publication April 22, 1975. 